\title{
Polychlorinated Dibenzo-p-Dioxins and Dibenzofurans in Surface Sediments from the Estuary Area of Yangtze River, People's Republic of China
}

\section{Y. Z. Sun, ${ }^{1}$ B. Zhang, ${ }^{1}$ L. R. Gao, ${ }^{1}$ Z. T. Liu, ${ }^{2}$ M. H. Zheng ${ }^{1}$ \\ ${ }^{1}$ State Key Laboratory of Environmental Chemistry and Ecotoxicology, Research Center for Eco-Environmental Sciences, Chinese Academy of Sciences, Post Office Box 2871, Beijing 100085, People's Republic of China \\ ${ }^{2}$ Chinese Research Academy of Environmental Sciences, Beijing 100012, People's Republic of China}

\section{Received: 5 July 2005/Accepted: 17 August 2005}

Dioxins are a group of highly toxic, extremely anthropogenic compounds that give a potential health hazard to humans and other organisms. In vertebrates, PCDDs/PCDFs cause a broad spectrum of physiological disorders including weight loss, reproductive failure, thymic atrophy, hepatotoxicity, several types of dermal lesion, and immunotoxicity (Safe, 1990; Mocarelli et al. 1996; Luebke et al. 2001). To assess the environmental quality, many countries have monitored the level of PCDDs/PCDFs in various environmental samples including soil and sediment (Joelle et al. 2002; Rappe et al. 1997).

The Yangtze River, is the longest river in China, running 6300 kilometers. It is the third longest river in the world. Its basin, extending for some 2,000 miles from west to east and for more than 600 miles from north to south, drains a huge area in South China. The Yangtze River also carries more water than any other river in China. The water quality of the Yangtze River is well comprehended, but environmental monitoring was mainly focused on the total heavy metal, total phosphor, total nitrogen and TOC. There is little information on level of the trace persistent organic pollutants, so it is meaningful to investigate the sediments from the river mouth of the Yangtze River for studying the pollution status of the middle and lower reaches of the river. This study aimed to determine the level of the dioxins in the sediments from the river mouth and find out the transport character of the dioxins in the middle and lower reaches of the river. The patterns and levels of 2,3,7,8-substitued PCDDs/PCDFs in surface sediments from 6 typical sampling profiles in the river mouth areas, determined by HRGC/HRMS using ${ }^{13} \mathrm{C}$-labelled isotope dilution method. The work presented preliminary results on the concentrations, congener distribution characterize and sources of dioxins which would provide referential data for further study.

\section{MATERIALS AND METHODS}

The samples of surface sediments were collected in April, 2004, the sampling 


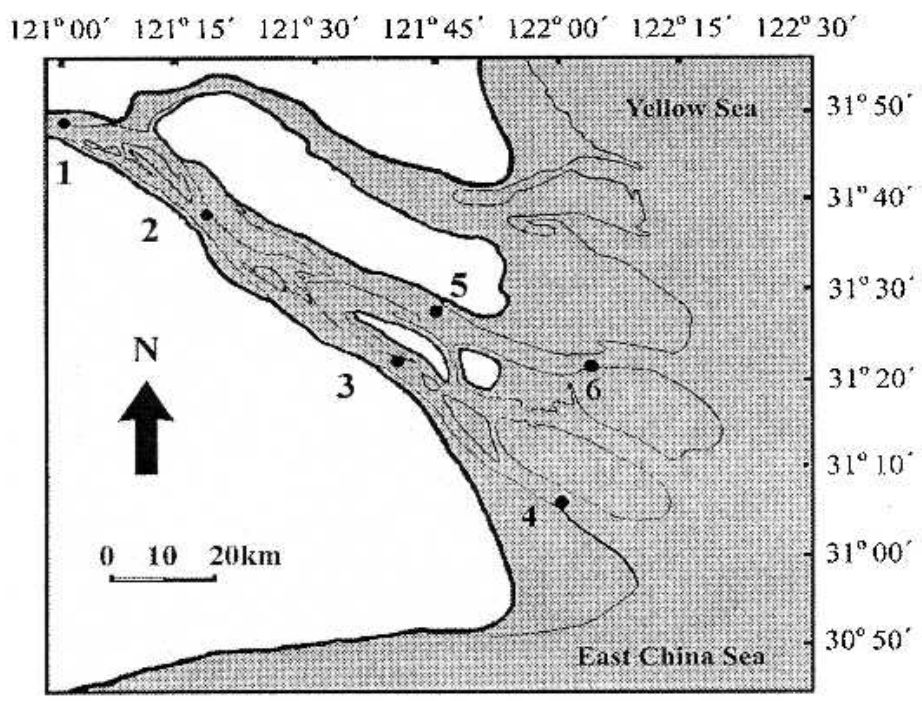

Figure1. Sample site

points were located in Shanghai estuaries near the river mouth (as shown in Figure 1), oriented by GPS, which were presented by 1 \# $\left(121^{\circ} 00.180 \mathrm{E}, 31\right.$

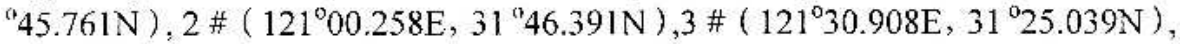
4 \# $\left(121^{\prime \prime} 59.718 \mathrm{E}, 31^{\circ} 04.750 \mathrm{~N}\right), 5 \#\left(122^{\circ} 25.85 \mathrm{E}, 31^{\circ} 08.00 \mathrm{~N}\right), 6 \#$ $\left(122^{\circ} 04.77 \mathrm{E}, 31^{\prime \prime} 21.58 \mathrm{~N}\right)$, respectively. The samples obtained were kept in $-20^{\circ} \mathrm{C}$ refrigerator for storage until analysis.

The samples of the surface sediments were freezed dried $48 \mathrm{~h}$ before analysis, and sieved $(\Phi 1 \mathrm{~mm})$ to remove any bigger solid objects. Ten grams of sieved dry samples were measured accurately and spiked with ${ }^{13} \mathrm{C}$-labelled 2,3,7,8-substituted $\mathrm{PCDD} / \mathrm{Fs}$ congeners as surrogate(Cambridge Isotope Laboratories, USA ). The spiked samples were then extracted with toluene for 24 $\mathrm{h}$ in a Soxhlet extractor. The extract were concentrated to $1.0 \mathrm{~mL}$ using a rotary evaporator and spiked with ${ }^{13} \mathrm{C}$-labelled isotope clean-up standard solution (Cambridge Isotope Laboratories, USA). The bulk of the co-extracted organic materials were removed by passing the extract through the multiple-layered chromatographic columns stuffed with the following series of activated silica, sodium oxyhydrogen, acid sulpharic and silver nitrate silica from up to down, The extract collected were concentrated to $1 \mathrm{ml}$ and then passed through basic aluminum oxide chromatography column, eluted with $100 \mathrm{ml} 2 \%$ dichlomethane/hexane $(\mathrm{v} / \mathrm{v})$ and the eluate was abandoned, followed by elution with $50 \mathrm{~mL} 50 \%$ dichlomethane/hexane $(\mathrm{v} / \mathrm{v})$. The resulting eluate was concentrated to $10 \mu \mathrm{L}$ and added with ${ }^{13} \mathrm{C}$-labelled standards (Cambridge Isotope Laboratories, USA) for quantification just prior to GC/MS analysis. 
An Agilient 6890 HRGC equipped with an AutoSpec Ultima HRMS (Water Micromass, Manchester, UK). A DB-5 quartz capillary column with dimensions of $60 \mathrm{~m} \times 0.25 \mathrm{~mm}$ id $(0.25 \mu \mathrm{m}$ film thickness $)$ was used. The gas chromatograph was operated in the splitless mode with a velocity of $1.2 \mathrm{ml} / \mathrm{min}$ in the constant flow mode, and the injection volume is $1 \mu \mathrm{L}$. The injector and transfer line were $280^{\circ} \mathrm{C}$ and $290^{\circ} \mathrm{C}$, respectively. The GC oven temperature was programmed as follows: initial temperature of $160^{\circ} \mathrm{C}$ was held for $3 \mathrm{~min}$, increased at a rate of $7.5^{\circ} \mathrm{C} / \mathrm{min}$ to $220^{\circ} \mathrm{C}$ (held for $16 \mathrm{~min}$ ), and increased at $5^{\circ} \mathrm{C} / \mathrm{min}$ to $235^{\circ} \mathrm{C}$ (held for $7 \mathrm{~min}$ ), then $5^{\circ} \mathrm{C} / \mathrm{min}$ to $330^{\circ} \mathrm{C}$ (held for $1 \mathrm{~min}$ ). The MS operating condition were as follows: The ionization was carried out in the electron impact (EI) mode $(35 \mathrm{eV})$. The tune parameters were set as follows: resolution $\geqq 10,000$; temperature of ion source, $250^{\circ} \mathrm{C}$; current of ion trap, $600 \mathrm{~mA}$; voltage of the photoelectric manifold, $350 \mathrm{~V}$; reference material, high boiling-point PFK; injection temperature of reference, $140^{\circ} \mathrm{C}$. The collective mode was chosen as selected-ion monitoring mode (SIM).

\section{RESULTS AND DISSCUSSION}

The results of the surface sediments from the river mouth, expressed in $\mathrm{pg} / \mathrm{g}$ dry weight for the 17 toxic 2,3,7,8-substituted congeners and also in international toxic equivalence factors (I-TEQ) are given in Table 1. The recoveries of the samples are in the range from 50.3 to $92.8 \%$.

Table 1. Concentrations and TEQ of 2,3,7,8-substituted PCDD/Fs in sediment samples (pg/g).

\begin{tabular}{lllllll}
\hline & 1 & 2 & 3 & 4 & 5 & 6 \\
\hline 2378-TCDF & 0.06 & $<0.02$ & 0.01 & 0.25 & 0.22 & 0.15 \\
12378-PeCDF & 0.04 & $<0.02$ & 0.03 & 0.12 & 0.12 & 0.12 \\
23478-PeCDF & 0.04 & $<0.02$ & 0.02 & $<0.06$ & 0.15 & $<0.04$ \\
123478-HxCDF & 0.13 & 0.02 & 0.05 & 0.21 & 0.45 & 0.246 \\
123678-HxCDF & 0.07 & 0.02 & 0.03 & 0.12 & 0.23 & 0.13 \\
$234678-H x C D F$ & 0.03 & 0.02 & 0.01 & 0.11 & 0.14 & 0.13 \\
123789-HxCDF & 0.01 & $<0.02$ & 0.00 & 0.01 & 0.08 & 0.06 \\
1234678-HpCDF & 0.24 & 0.07 & 0.10 & 1.09 & 1.83 & 1.67 \\
1234789-HpCDF & 0.03 & $<0.01$ & 0.01 & 0.12 & 0.20 & 0.25 \\
OCDF & 0.21 & $<0.02$ & 0.11 & 5.6 & 5.09 & 10 \\
2378-TCDD & 0.02 & $<0.04$ & 0.01 & 0.01 & 0.03 & 0.01 \\
12378-PeCDD & 0.18 & 0.26 & 0.16 & 0.15 & 0.28 & 0.24 \\
123478-HxCDD & 2.5 & $<0.02$ & 1.81 & 2.1 & $<0.02$ & 3.1 \\
123678-HxCDD & $<0.02$ & $<0.02$ & $<0.02$ & 0.13 & $<0.02$ & $<0.02$ \\
123789-HxCDD & $<0.02$ & $<0.02$ & 0.01 & $<0.02$ & $<0.02$ & $<0.02$ \\
1234678-HpCDD & 4.4 & 2.9 & 3.7 & 4.7 & 5.7 & 4.6 \\
OCDD & 101 & 62 & 84 & 152 & 83 & 161 \\
TEQ & $\mathbf{0 . 5 6}$ & $\mathbf{0 . 2 9}$ & $\mathbf{0 . 4 2}$ & $\mathbf{0 . 6 3}$ & $\mathbf{0 . 5 3}$ & $\mathbf{0 . 7 8}$ \\
\hline
\end{tabular}


From Table 1, it could be seen that OCDD had the highest value in all cases, followed by $1,2,3,4,6,7,8-\mathrm{HpCDD}$ or OCDF. The pattern of PCDD/Fs in the sediments characterized by high OCDD might be relevant to use of sodium pentachlorophenate (Na-PCP) in the middle and lower reaches of the Yangtze River, in which 12 provinces, municipalities and autonomous regions had used as a valid drug to control the spreading of snail borne schistosomiasis from 1960 s to 1990s. PCDD/Fs entered into the water environment with Na-PCP as inevitable byproducts and then accumulated in the suspended particles by adoption and subsided, transferred into the sediments, which was consistent with other studies result before (Bao et al.1995). Furthermore, the pattern is similar to the former result obtained in other schistosomiasis epidemic area (Zheng et al. 1997, 2001). So it could be concluded that Na-PCP used in the middle and upper reaches is the main input source of PCDD/Fs. The residue of 2,3,7,8-TCDF from sampling point 4,5 ,and 6 might explained by effluent pollution from the paper and pulp factories which used chlorine bleaching technical process.

The TEQ in the selected sediment samples ranged from 0.29 to $0.78 \mathrm{ng} / \mathrm{g}$ (d.w) with an average of $0.54 \mathrm{ng} / \mathrm{g}$ (d.w). In view of the measuring results, there is not much serious dioxins pollution in the Shanghai estuary of the Yangtze River due to the dilution of large amount of water and sand from upper reaches. But the concentration of PCDD/Fs is higher compared with other studies in China (Yang et al. 2004), so further investigation is necessary.

Acknowledgements. This study was supported by National Natural Science Foundation of China (40332023) and National 973 project of China (Grant no. 2002CB412401)

\section{REFERENCES}

Bao ZC, Kang JX, Zhao LW (1995) Analysis of Polychlorinated dibenzo-p-dioxins and dibenzofurans in pentachlorophenol and sodium pentachlorophenate. Environ Chem (China) 14:317-321

Joelle A. Prange, Caroline Gaus, Olaf Päpke, Jochen F. Müller (2002) Investigations into the PCDD contamination of topsoil, river sediments and kaolinite clay in Queensland, Australia. Chemosphere 46:1335-1342

Luebke RW, Copeland CB, Daniels M, Lambert AL, Gilmour MI (2001) Suppression of allergic immune responses to house dust mite (HDM) in rats exposed to 2,3,7,8-TCDD. Toxicol Sci 62:71-79

Mocarelli P, Brambilla P, Gerthoux PM, Patterson DGJ, Needham LL (1996)

Change in sex ratio with exposure to dioxin. Lancet 348, 409

Rappe C, Andersson R, Bonner M, Cooper K, Fiedler H, Howell F, Kulp SE, Lau $C$ (1997) PCDDs and PCDFs in soil and river sediment samples from a rural area in the United States of America. Chemosphere 34:1297-1314 
Safe S (1990) Polychlorinated biphenyls (PCBs), dibenzo-pdioxins (PCDDs), dibenzofurans (PCDFs), and related compounds: environmental and mechanistic considerations which support the development of toxic equivalency factors (TEFs). Toxicology 21:51-87

Zheng $\mathrm{MH}$, Bao $\mathrm{ZC}$, Wang $\mathrm{KO}$, Yang $\mathrm{H}$, Xu XB (1997) Polychlorinated dibenzo-p-dioxins and dibenzofurans in lake sediments from Chinese schistosomiasis area. Bull Environ Contam Toxicol 59:653-656

Zheng MH, Chu SG, Sheng GY, Min YS, Bao ZC, Xu XB (2001) Polychlorinated dibenzo-p-dioxins and dibenzofurans in surface sediments from Peal River Delta in China. Bull Environ Contam Toxicol 66: 504-507

Yang YL, Shi SX, Pan J, Li HL, Li GG, Gao H, Zhou C, Li Y, Shi L, Jones K (2004) Congener distribution of dioxin-like compounds in sediments from the Nansi Lake, China. Environ Chem (China) 23: 549-555 